\title{
Nomes e pronomes na Língua Portuguesa: a questão sexista no idioma e na academia
}

\author{
Sandra Nodari' (iD 0000-0002-9019-6697
}

'Universidade Positivo, Curitiba, PR, Brasil.81280-330 - jornalismo@up.edu.br

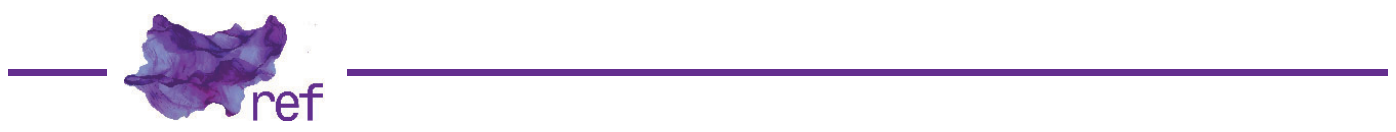

Resumo: Neste ensaio, discuto a invisibilidade de pesquisadoras por conta das normas da Língua Portuguesa e das normas de referenciação das publicações acadêmicas pelo viés de gênero com relação à creditação de mulheres. É regra geral, com exceção de algumas revistas feministas, que autores e autoras sejam apresentados em artigos, dissertações e teses pelo sobrenome, o que pode reduzir a percepção das mulheres que são citadas em pesquisas científicas. As discussões com relação ao sexismo do idioma, trazidas por vezes pela imprensa a partir de discussões sociais, são considerações aqui tratadas. A pergunta que surge é se pode haver um movimento de revisão da forma de creditar as mulheres em trabalhos científicos. Para tanto, após a revisão da literatura, haverá uma proposta de que a creditação das autoras mulheres seja feita de forma completa, com nome, sobrenome e uso dos pronomes adequados.

Palavras-chave: gênero; autoras; mulheres; normas de publicação; invisibilidade.

Names And Pronouns in the Portuguese Language: The Sexist Issue in Language and in Academia

Abstract: This essay discusses the invisibility of female researchers because of the Portuguese language standards and also because of the gender bias in relation to the accreditation of women present in the academic publication standards. It is a general rule, with the exception of some feminist magazines, that the authors are presented in articles, dissertations and theses, by surname, which can reduce the perception of women cited in scientific research. Discussions in relation to the language sexism brought up by the press from social discussions are also considered. Can there be a movement to revise the way of crediting women in scientific work? For such, after reviewing the literature, there will be a proposal that the female authors' accreditation be done in full, with first and last name and with the appropriate pronouns.

Keywords: Gender; Authors; Women; Publishing Standards; Invisibility.

Nombres y pronombres: la cuestión sexista en el idioma Portugués y en la academia Resumen: Este ensayo discute la invisibilidad de las investigadoras debido a las reglas de la lengua portuguesa y los estándares para referenciar publicaciones académicas por sesgo de género en relación a la acreditación de mujeres. Es una regla general, a excepción de algunas revistas feministas, que las autoras se presenten en los artículos, disertaciones y tesis, por apellido, lo que puede reducir la percepción de mujeres citadas en las investigaciones científicas. También se consideran las discusiones en relación al sexismo del lenguaje, a veces planteadas por la prensa a partir de las discusiones sociales. La pregunta que surge es si puede haber un movimiento para revisar la forma de acreditar a las mujeres en el trabajo científico. Por lo tanto, luego de revisar la literatura, se propondrá que la acreditación de las autoras se realice en su totalidad, con nombre y apellido y con los pronombres adecuados.

Palabras-clave: género; sexismo; mujeres; normas de acreditación; invisibilidad. 


\section{Os sobrenomes das autoras as reconhecem como mulheres?}

A história ocidental nos conta que as primeiras mulheres a escreverem textos literários e que queriam ter seus livros lidos eram obrigadas a usar pseudônimos masculinos para fugir ao preconceito de que mulher não devia, nem era capaz de escrever. Nomes de grandes escritores europeus como George Eliot (Inglaterra) e Georg Sand (França) são exemplos desta situação. Ambos eram pseudônimos de escritoras notáveis, a inglesa Mary Ann Evans e a francesa Amantine Dupin, mas que só tiveram sucesso porque não assinaram seus nomes reais.

Estes casos, ocorridos até o século XIX, são discutidos por Virgínia Woolf (2014) em seu livro Um Teto Todo Seu quando lembra escritoras que abriram caminho para que a literatura escrita por mulheres entrasse na história. Woolf $(2014$, p. 62) sugere que elas sempre escreveram, mas não tiveram seus nomes relacionados às suas obras: "Anônimo, que escreveu tantos poemas sem assiná-los, foi muitas vezes uma mulher". A ironia presente no texto é usada para nos lembrar da luta das mulheres por reconhecimento e autorização em um mundo onde as decisões eram e são masculinas.

O texto de Virgínia Woolf foi escrito em de 1928 e era base de uma palestra a estudantes universitárias quando foi convidada a tratar do tema Mulheres e Ficção, mas ela acabou decidindo por chamar atenção para uma questão que achou fundamental naquele momento: "Uma mulher precisa ter dinheiro e um teto todo seu, um espaço próprio, se quiser escrever ficção" (2014, p. 10). Ela agradece à tia Mary Beton, que Ihe deixou uma herança de 500 libras anuais até o fim da vida, o que lhe permitiu escrever o que e como quisesse, assinando seu próprio nome: "Comida, casa e roupas são minhas para sempre" (2014, p. 47).

A noção de pessoa privilegiada, discutida por Woolf nos textos, demonstra que, para além de uma casa, há necessidade de permissão para ocupar determinados lugares, sejam físicos ou na sociedade. Desde que as mulheres conquistaram esta "permissão" social de assinar os textos por elas escritos, bem como o de ocupar postos nas universidades, uma das formas de reconhecer uma autora é por meio de seu nome.

As normas acadêmicas de publicação, em sua maioria, organizam os créditos das publicações pelo sobrenome. Tanto ABNT, quanto Harvard, AVA, APA, além de normas específicas de universidades, a serem seguidas em dissertações e teses e publicadas em seus repositórios, entre outros códigos de normas para publicação, buscam no sobrenome a forma de creditar autores e autoras. Este ensaio quer discutir o que esta prática significa e de que maneira é possível visibilizar textos de autoras.

É fato que as mulheres são menos citadas em publicações acadêmicas, em reportagens de jornalismo e em documentos públicos, questões que serão apresentadas e discutidas no decorrer deste ensaio, o que justifica sua escritura. Segundo a pesquisa Gender in the Global Research Landscape (ELSEVIER, 2017), na produção de artigos científicos, mulheres brasileiras e portuguesas ocupam $49 \%$ dos nomes catalogados pela editora Elsevier. Apesar de ser menos da metade, ainda assim é o maior percentual numa lista de 12 nações, sendo que no mundo apenas $28 \%$ das pesquisadoras seriam mulheres. Regina Dalcastagné (2012) afirma que a maioria dos autores brasileiros são homens brancos, de classe média, professores ou jornalistas. Ela aponta que as mulheres são menos publicadas que os homens, porém, afirma que "não é possível dizer se as mulheres escrevem menos ou se têm menos facilidade para publicar nas editoras mais prestigiosas (ou ambos)" (DALCASTAGNÉ, 2012, p. 31).

Raquel da Conceição Santos, Hellen Rafaela Pinheiro Figueiredo e Maria do Socorro Castro Hage (2019), no artigo "Mulheres e Produção do Conhecimento Científico: uma reflexão necessária", lembram que, a partir do século XIX, a ciência moderna girava em torno da predominância de cientistas homens, brancos, ocidentais e de classes abastadas: "eram os homens que estavam à frente" do "saber e nas produções acadêmicas, como se este fosse o único dotado de razão e sabedoria, ocasionando uma exclusão de mulheres neste meio". Apesar de haver mulheres construindo o conhecimento científico, elas eram "invisibilizadas" (SANTOS et al., 2019). As autoras explicam que nas últimas décadas do século XX houve aumento no reconhecimento de mulheres cientistas, porém, com discriminação:

Pelo fato de serem mulheres, algumas posturas masculinas buscavam categorizá-la mediante aspectos considerados de natureza "feminina", ocasionando, uma divisão sexual de trabalho, assim, as mulheres foram conquistando espaços em áreas de conhecimento que não era fortemente ocupada por homens, desde sempre era marginalizada, sem poder de decisão, não era vista como sujeito de direitos, devido às questões ligadas ao gênero.

Segundo as autoras, o fato de as ciências humanas não serem compreendidas como ciências masculinas acarretou a ocorrência da diminuição dos homens em determinados setores, o que pode ter permitido e provocado o aumento da inserção feminina. A pesquisa foi realizada junto ao PPGSA - Programa de Pós-Graduação em Sociologia e Antropologia da Universidade Federal da Paraíba. "As análises feitas com os dados do PPGSA evidenciaram 
a crescente participação e lugar ocupado por mulheres no campo da pesquisa científica, demonstrando a relevância das produções realizadas por elas nos estudos sócio-antropológicos sobre as realidades amazônicas", apontam as autoras (SANTOS et al., 2019).

Salete Silva Farias e Alcina de Oliveira Martins (2018), no artigo "Invisibilidade Feminina e Representações Sociais de Gênero em Tecnologia e Ciências" (2018), acompanharam o Global Gender Gap Report, relatório que quantifica a desigualdade de gênero nas áreas de saúde, educação, economia e política, por meio de seu progresso ao longo dos anos, e verificaram que, depois de uma década de estudos, "o progresso ainda é lento" no setor de educação, que engloba as ciências, tecnologias, engenharias e matemáticas.

As mulheres continuam sub-representadas na área das STEM (Science, Technology, Engineering, and Mathematics), onde o global gender gap se mantém nos $47 \%$, sendo $30 \%$ homens e $16 \%$ mulheres. Segundo este mesmo Relatório, tal deve-se à existência de estereótipos negativos e consequente falta de modelos positivos, o que faz com que meninas e mulheres não tenham aspirações, no sentido de seguir a carreira das STEM (FARIAS; MARTINS, 2018, p. 731).

Uma das razões da menor procura, como explicam as autoras, é a ausência e a invisibilidade de mulheres desses setores da educação nos veículos de comunicação e na mídia em geral, o que acaba por influenciar as crenças sociais e a criação dos estereótipos. "Com representações mais positivas na mídia, num campo que é dominado por homens, mais mulheres poderiam considerar a tecnologia como uma opção, diminuindo as percepções negativas das mulheres e aumentando as suas aspirações de liderança" (FARIAS; MARTINS, 2018, p. 737). A invisibilidade forçada pela falta de modelos femininos na área de tecnologia pode criar a falsa sensação de que não há mulheres nesta área da ciência "visto que, embora existam modelos, estes não são apresentados na mídia e/ou na escola e na literatura vigente, devido a uma cultura educacional predominantemente masculina" (FARIAS; MARTINS, 2018, p. 738).

Para além de serem menos publicadas pelos veículos de comunicação, pela academia e pelas editoras, ainda há a questão de serem menos reconhecidas, uma vez que seus nomes não as creditam como mulheres, quando apresentadas apenas pelo sobrenome e por suas iniciais. Nesse caso bastante praticado por revistas científicas, o leitor de uma publicação pode não ter a menor ideia de se algum dos sobrenomes listados nas referências bibliográficas finais seja de uma autora. Ao ler, por exemplo, QUADROS. S. ou MOREIRA. M., não há como saber a qual gênero pertence quem escreveu o texto. Porém, numa cultura onde o homem historicamente produz e publica mais, é comum que os sobrenomes sejam ligados a pesquisadores e não a pesquisadoras. Alterar o modo como as mulheres são creditadas em trabalhos científicos é urgente.

Como a Língua Portuguesa determina que o gênero gramatical masculino se sobreponha ao feminino no caso de plurais e pronomes, e em um cenário onde a maioria dos autores publicados é de homens, a pergunta que surge é: a impressão ao leitor pode ser a de que todos os sobrenomes remetam a autores masculinos? Outra questão a ser refletida é: a valorização do masculino, trazida ao longo da história, pode refletir na academia e nos textos científicos quando os nomes das mulheres não são assinados?

O método encontrado para buscar as reflexões aqui propostas foi o ensaio teórico que, por ser de natureza científica, trata-se de uma discussão sobre um tema cuja metodologia é a fundamentação teórica a partir da revisão da literatura acadêmica, mas sem ser apenas um trabalho de estado da arte. A intenção deste texto científico é, a partir do caráter dissertativo, defender um ponto de vista ou uma ideia de certa forma nova, sem a pretensão de encerrar o assunto, como afirmam Sandro Soares, Icaro Picolli e Jacir Casagrande (2018, p. 331).

O ensaísta necessita ter competências para expor e defender ideias; razoabilidade para tratar a dialética necessária à discussão; bom senso e autocontrole para não se deixar levar por motivos apaixonados e de caráter emocional.

Nesse trabalho, tem-se como objetivo principal: refletir acerca das publicações que tratam da forma como a Língua Portuguesa se relaciona com questões de gênero e sexo, tendo como tese o fato de que o idioma, sendo machista, em sua forma, pode prejudicar a visibilidade das autoras. Outra intenção é trazer uma proposta de citação que seja mais inclusiva para as mulheres, dando-lhes visibilidade nas publicações acadêmicas, levando em conta pesquisadoras que já iniciaram esse movimento.

A discussão aqui proposta é atual e contemporânea ao momento histórico em que mulheres no mundo todo militam pela igualdade de gênero. A visibilidade é uma das principais bandeiras de luta das Marchas Feministas, também chamadas de Marcha Mundial das Mulheres ou Greve Internacional das Mulheres, realizadas no dia 08 de março de cada ano no Brasil e em Portugal, bem como ao redor do mundo. No Brasil, as primeiras manifestações nesta data começaram em 2000 (MARCHA MUNDIAL DAS MULHERES, s.d.). Este ensaio se justifica por tratar da visibilidade das autoras de textos científicos. 


\section{Nomes a partir do gênero}

Uma das formas de reconhecer uma autora é porque ela se apresenta como mulher. Judith Butler (2003, p. 57-58) encerra o primeiro capítulo do livro Problemas de Gênero na busca em definir o que é o feminino e, para isso, vai analisar a frase mais reproduzida de Simone Beauvoir.

Se há algo de certo na afirmação de Beauvoir de que ninguém nasce e sim torna-se mulher decorre que mulher é um termo em processo, um devir, um construir de que não se pode dizer com acerto que tenha uma origem ou um fim. Como uma prática discursiva contínua, o termo está aberto a intervenções e re-significações.

Partindo do fato de que uma mulher se apresenta como mulher, independentemente de seu sexo biológico, mas a partir de sua identidade, o nome é uma das maneiras de indicar o gênero da autora. Embora existam nomes que são masculinos e femininos e nomes que sirvam a todos os gêneros, na maioria dos casos da Língua Portuguesa é possível reconhecer nomes femininos e masculinos. Talvez esta não seja uma situação comum a outros idiomas, mas, no Brasil e em Portugal, a busca pela troca do nome civil pelo nome social é um indicativo de que o gênero está marcado no nome de quem se apresenta.

A relevância do nome como identificador de gênero ganhou notoriedade nos últimos anos, quando pessoas começaram a trocar de nome, quando se identificavam com um gênero diferente do sexo biológico. O reconhecimento médico e dos pais ao nascer, documentado oficialmente por meio de registros de identificação (como a certidão de nascimento no Brasil e os assentos de nascimento em Portugal) passou a ser questionado na Justiça. A troca do nome se dava, inicialmente, de maneira informal, porém, o assunto tomou tamanha importância que os países começaram a discutir a adoção de novo nome de forma oficial e documentada, a partir da identificação de gênero.

Portugal, em 2011 , se tornou o sexto país da Europa, depois de Alemanha, Espanha, Itália, Reino Unido e Suíça, a permitir, por meio de lei, a alteração de mudança de sexo e de nome próprio no registro civil a pessoas que tenham sido clinicamente diagnosticadas. "A presente lei regula o procedimento de mudança de sexo no registo civil e correspondente alteração de nome próprio" (PORTUGAL, 2019). A lei foi proposta no ano anterior, seguindo uma orientação da Comunidade Europeia.

No Brasil, em 28 de abril de 2016, a Presidenta Dilma Rousseff assinou o decreto de lei número 8727, que "Dispõe sobre o uso do nome social e o reconhecimento da identidade de gênero de pessoas travestis e transexuais no âmbito da administração pública federal direta, autárquica e fundacional" (BRASIL, 2016). O decreto define que nome social é a "designação pela qual a pessoa travesti ou transexual se identifica e é socialmente reconhecida" e que identidade de gênero é a

dimensão da identidade de uma pessoa que diz respeito à forma como se relaciona com as representações de masculinidade e feminilidade e como isso se traduz em sua prática social, sem guardar relação necessária com o sexo atribuído no nascimento.

E determina que o nome social seja adotado em todo o território brasileiro por todos os órgãos da administração pública federal, autarquias e fundações que "deverão adotar o nome social da pessoa travesti ou transexual, de acordo com seu requerimento e com o disposto neste Decreto". Os cadastros e documentos destes órgãos devem ter um campo para registro de nome social e também do nome civil, sendo o primeiro destacado do segundo: "deverão conter o campo 'nome social' em destaque, acompanhado do nome civil, que será utilizado apenas para fins administrativos internos".

Em março de 2018, o Supremo Tribunal Federal Brasileiro (SUPREMO TRIBUNAL FEDERAL, 2018) decidiu que pessoas interessadas em trocar o nome civil pelo nome social, nas certidões de nascimento, têm o direito de fazer isso procurando diretamente um cartório de Registro Civil, sem a necessidade de estarem acompanhadas de um advogado ou defensor público quando maiores de 18 anos, se menores, precisam de ação judicial.

Regulamentar a permissão para a troca de nome social, nos dois países de Língua Portuguesa, é uma forma de alterar o idioma, sobretudo de transformá-lo e atualizá-lo conforme as necessidades sociais, uma vez que pessoas nascidas com um sexo biológico passam a ser chamadas pelos pronomes relacionados à sua identidade de gênero.

Se o feminismo é, acima de tudo, uma forma de ativismo, há outras formas, também, ligadas a diferentes gêneros que lutam pela visibilidade. É importante ressaltar que há um sem número de confusões criadas a partir das transformações do idioma, principalmente, relacionadas aos pronomes usados a quem muda de nome. No Brasil, o caso da cantora Pabllo Vittar é um dos exemplos. Pabllo é um nome masculino, mas a figura que a representa é ora a feminina, ora a masculina, sendo a primeira que a representa na maioria das vezes. 
Duas imagens exibidas pelo Instagram do Estadão, em 15 de maio de 2020, demonstram as duas performances da artista, sendo que, na primeira, Pabllo Vittar performa uma personagem masculina ou andrógena e, na segunda, uma personagem feminina (ESTADÃO, 2020). As fotos são de uma postagem cujo título é "Pabllo Vitar é nova garota propaganda da Calvin Klein em Campanha LGBT", \#ProudlnMyCalvins, que traz a cantora como protagonista. Um trecho do post explica que "O objetivo é fazer uma homenagem durante as comemorações do orgulho LGBTQ+, que ocorre em junho", que traz uma frase da artista: "Espero que outras garotas e outros garotos sejam inspirados por isso e acreditem em seus sonhos" (ESTADÃO, 2020).

O Pabllo e a Pabllo são formas usuais de referir-se à artista, que admite não ter preferência. Em uma leitura crítica da persona pública da performer, Rose de Melo Rocha e Danilo Postinguel (2017) afirmam que é necessário assumir um olhar para o "entre" masculino e feminino. Essa afirmação faz todo o sentido quando analisamos a artista.

É neste entre (em vários entres, na verdade) que se afirma a construção plástica da drag, cantora, performer, a mesma que, "desmontada", aparece em vídeos gravados do celular, circulando por ruas e calçadas nos intervalos de um show, fe-menino que ora é a diva maquiada, erotizada, com seu aparecimento luxuoso e lascivo, e logo mais é a menino-jovem andrógina, de sobrancelhas raspadas e cabelos curtíssimos, perguntando-se se encontrará algum boy na cidade estrangeira por onde transita.

Este exemplo, por ser de um fenômeno pop para os brasileiros, serve a essa análise porque dá visibilidade à discussão do idioma: o fato de ela ser chamada por entrevistadores algumas vezes de ele, outras de ela, promove discussões entre os fãs e entre os cidadãos mais conservadores - seja nas falas de apoio ou de manifestações de ódio. Embora esse exemplo fuja da questão da creditação das autoras, os parênteses foram criados por conta da visibilidade da discussão e do uso dos pronomes e artigos, que configuram valor de feminino e masculino na Língua Portuguesa.

\section{Existe preconceito de gênero na Língua Portuguesa?}

É comum ouvir de mulheres militantes, ao conversarem com plateias, o seguinte cumprimento: "Boa noite a todas e a todos!"; "Bom dia alunas e alunos!". Estas formas de comunicação surgiram para dar conta de algo que a Língua Portuguesa (e outras línguas oriundas do latim) tem como característica, que é o uso do gênero masculino como forma de reduzir o gênero plural. Alunos e alunas viram alunos, por exemplo.

Grada Kilomba (2019), teórica do feminismo negro, nascida em Lisboa, contribui com essa discussão pela reflexão que traz acerca da inflexão dos pronomes da Língua Portuguesa no gênero feminino e masculino, por isso, recorremos a ela em diversos momentos deste artigo para tratar do que chama de preconceito do idioma.

Quando escrevi o paper "Facebook as a video production and exhibition platform used by journalism students: a case study of Rede Teia (Brazil)" (Sandra NODARI, 2019) para discutir o uso do conceito de lugar de fala em um projeto dentro de uma disciplina de graduação do curso de Jornalismo - e que foi apresentado em um congresso de língua inglesa, ${ }^{1}$ a questão de gênero na Língua Portuguesa exigiu maior reflexão por conta da tradução. O texto foi escrito originalmente em Língua Portuguesa, utilizando termos no gênero feminino e masculino para alunos e alunas, professores e professoras, entrevistados e entrevistadas, apresentadores e apresentadoras. Na tradução para o inglês, foi necessário fazer uma escolha porque, naquela língua, o gênero é neutro, na maioria das vezes.

Em uma primeira reflexão, parecia que, ao utilizar substantivos, pronomes e adjetivos nos gêneros masculino e feminino, estaríamos evoluindo em direção a uma valorização do feminino, porém, em idiomas em que o gênero é neutro, isso é desnecessário. A leitura de Memórias da Plantação permitiu perceber que Kilomba (2019) também passou por essa reflexão quando decidiu traduzir sua tese que inicialmente tinha sido escrita em inglês. Ao traduzir o texto para a Língua Portuguesa, ela optou por inserir uma introdução que explicasse as especificidades com relação à flexão de gênero.

Escrevo esta Introdução, inexistente na versão original inglesa, precisamente por causa da língua: por um lado, porque me parece obrigatório esclarecer o significado de uma série de terminologias que, quando escritas em português, revelam uma profunda falta de reflexão e teorização da história e herança coloniais e patriarcais, tão presentes na língua portuguesa (KILOMBA, 2019, p. 14).

A herança patriarcal e o machismo no idioma trouxeram uma discussão bastante acirrada quando a primeira mulher foi eleita para assumir a Presidência da República, em 2010, no Brasil,

\footnotetext{
Apresentado oralmente em WPEC-Paris (2019) - Congresso Mundial de Professores de Jornalismo e publicado nos anais do evento. Disponível em https://www.academia.edu/42017611/Facebook as a Video Production and Exhibition_Platform_Used_by_Journalism_Students_A_Case_Study_of_Rede_Teia_Brazil_.
} 
e muito se questionou sobre o uso da flexão para o feminino ao chamá-la por seu cargo. Era correto utilizar presidenta Dilma Roussef ou o substantivo presidente não permite variação, por ser comum aos dois gêneros? Apesar do posicionamento de Dilma, sobre querer ser chamada de presidenta (como mostra a Figura 1), houve divergência entre especialistas com relação à permissão de uso da palavra no gênero feminino, e muitos textos foram escritos para discutir se a Língua Portuguesa seria machista e qual seria a dimensão política de um idioma.

Figura 1: Presidenta Dilma Roussef

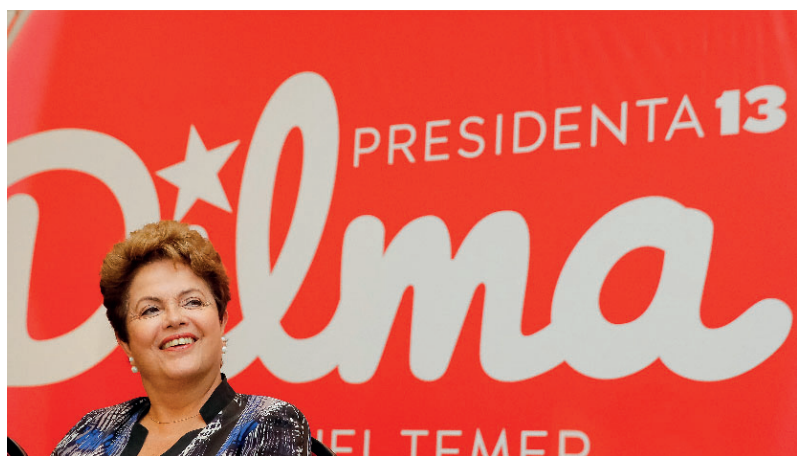

Fonte: Roberto Stuckert Filho

\#PraTodoMundoVer: Foto da presidenta Dilma Roussef sorrindo e olhando para o infinito. Ela veste uma blusa colorida que se vê parcialmente, e tem atrás de si um grande banner vermelho onde se lê em letras brancas: "Dilma Presidenta 13".

Cássio Florêncio Rubio e Fábio Fernandes Torres (2018) discutem a forma como os senadores e as senadoras do Brasil fizeram uso dos termos presidente ou presidenta para interrogar Dilma Roussef no processo de impeachment.

Os autores concordam que ainda não há "consenso sobre o emprego de uma ou outra forma, ou, ainda, sobre a possível aceitação das duas formas como mais um processo de variação do português brasileiro", apesar "dos comprovados registros das duas formas nos dicionários e vocabulários ortográficos" (2018, p. 493) e pela aceitação por "inúmeros gramáticos normativos e lexigráficos" (2018, p. 497). Ao fazer uma revisão da literatura sobre o substantivo, concluem que:

Cabe destaque o registro, nas duas acepções da forma presidenta, da palavra mulher, restringindo seu uso ao sexo feminino, diferentemente do que se registra na forma presidente, que apresenta, nas duas primeiras definições, a palavra pessoa, que amplia seu emprego para ambos os sexos. A terceira acepção da forma presidente, contudo, específica para o cargo de presidência da república, apresenta-se delimitada ao sexo masculino pelo emprego do artigo o (RUBIO; TORRES, 2018, p. 497).

Da votação pelo impeachment, em 29 de agosto de 2016, participaram 48 senadores que usaram o substantivo 232 vezes em suas falas, sendo que a forma presidente foi usada $62,5 \%$ (145 vezes) e em 37,5\% (87 vezes) foi usada a forma presidenta (RUBIO; TORRES, 2018, $\mathrm{p}$. 497). O resultado da pesquisa considera que "a alternância das formas presidente e presidenta é influenciada, predominantemente, por fatores extralinguísticos ligados à ideologia política dos/das parlamentares" (RUBIO; TORRES, 2018, p. 520).

Os autores perceberam, também, que houve "maior sensibilidade feminina na determinação e reconhecimento da identidade de gênero no discurso, com as mulheres tendendo mais ao emprego da forma presidenta do que os homens" (RUBIO; TORRES, 2018, p. 521). A discussão sobre como chamar Dilma Roussef se manteve durante o primeiro mandato (2010-2014), a reeleição (2014) e o processo de impeachment (2016), e se mantém ainda hoje, quando alguns a chamam de ex-presidenta e outros de ex-presidente.

Tanto o caso de Pabllo Vittar quanto o de Dilma Roussef traz à tona comportamentos sociais tornados como decisivos na hora de chamar uma pessoa por sua identidade de gênero. Se flexão para o masculino e para o feminino já é suficiente para criar divisão entre especialistas da Língua Portuguesa e da população em geral, pensar nas outras categorias de gênero é perceber que existe mesmo a necessidade de discutir a fundo os preconceitos de uma sociedade. Para Kilomba (2019, p. 14), esta necessidade faz parte da evolução política já ocorrida nos idiomas inglês e alemão, mas que na língua portuguesa "continua ancorada a um discurso colonial e patriarcal".

Se o gênero masculino e feminino já é suficiente para buscar a atualização do idioma como dar conta das categorias que deixam de fora os LGBTQ+? Somente as várias siglas utilizadas no Brasil para referir-se a lésbicas, gays, bissexuais, travestis, transexuais, não binários, intersexuais e assexuais, como LGBTT (Marcia TIBURI, 2018), LGBTTQIA+ (KILOMBA, 2019), LGBTs, LGBTQIA, LGBT ou LGBTI podem trazer certa dificuldade geral na hora de referir-se ao tema (ver o caso de Beatriz Preciado (2014)). ${ }^{2}$

\footnotetext{
2 Estas questões estão presentes neste ensaio porque é preciso pensar, para além das mulheres, nas pessoas que possuem outras identificações de gênero e buscam por visibilização de autoria. $O$ filósofo espanhol Paul B. Preciado, nascido Beatriz Preciado, em seu livro Manifesto contrassexual (2014), critica as categorias fixas de identidade principalmente ligadas a sexo e gênero, consideradas pelo autor como produto do contrato social heterocentrado. O Manifesto declara as tecnologias de gênero responsáveis pelo binarismo, propondo que se
} 
Em textos menos formais, o uso do x ou do @ são maneiras de tornar o gênero neutro ou não binário e tem sido uma opção adotada por pessoas ao escreverem "colegxs" ou "coleg@s", por exemplo, e que acabam sendo consideradas militantes da causa LGBTQI+. Tiburi (2018) usou outro recurso no título do seu livro Feminismo em comum, para todas, todes e todos. Segundo a autora, o uso do "e", em vez de x ou @, foi uma estratégia para não dificultar a acessibilidade do conteúdo por deficientes visuais, porque softwares de leitura não conseguem traduzir os códigos $x$ ou @.

Ao discutir aonde nos levará o feminismo, Tiburi $(2018$, p. 11) afirma que "nos leva à luta por direitos de todas, todes, e todos". A palavra "todes" usada por ela em seu livro vai designar uma forma de combater o sexismo da Língua Portuguesa: "Todes porque o feminismo liberou as pessoas de se identificarem somente como mulheres ou homens e abriu espaço para outras expressões de gênero - e de sexualidade - e isso veio interferir no todo da vida".

Adriana Baggio (2020) explica que "as mulheres escrevem metade dos artigos acadêmicos no Brasil; no entanto, são menos citadas, ocupam menos cargos no estrato hierárquico mais alto das instituições e ainda sofrem preconceito e boicotes na academia". A percepção de que há poucas mulheres escrevendo, pesquisando e publicando se dá "quando, por exemplo, pessoas citam autoras mulheres mas, sem se dar conta, usam artigos, pronomes e outras concordâncias no masculino".

Cada vez mais, vemos mulheres buscando refletir sobre como aumentar a percepção da presença de autoras na escrita acadêmica de maneira a continuar a luta por igualdade, que é uma das bases do movimento feminista. Neste momento histórico, a Língua Portuguesa é o espaço onde os confrontos ocorrem. "Como a língua escrita é a linguagem primordial da produção acadêmica, mostrar a presença do feminino por meio da língua é uma forma de aumentar o reconhecimento das mulheres cientistas e de estreitar a relação entre a ciência e o feminino" (BAGGIO, 2020). ${ }^{3}$

Será que essas discussões, das autoras contemporâneas e de textos atuais, podem indicar a necessidade de um movimento de revisão da Língua Portuguesa? Grada Kilomba (2019, p. 14) afirma que há "uma série de terminologias que, quando escritas em português, revelam uma profunda falta de reflexão e teorização da história e herança coloniais e patriarcais, tão presentes na língua portuguesa". Ela questiona ainda o fato da:

(...) ausência de termos, que noutras línguas, como a inglesa ou alemã, já foram[foi] criticamente desmontados[a] ou mesmo reinventados[a] num novo vocabulário, mas que na língua portuguesa continuam[continua] ancorados[a] a um discurso colonial e patriarcal, tornando-se extremamente problemáticos[a] (KILOMBA, 2019, p. 14).

Guilherme Mäder (2015, p. 64) afirma que o uso do gênero gramatical masculino para denotar o gênero humano, em conjunto com o gênero não marcado, mantém o sexismo gramatical. "Além da percepção de diferença de gênero (sexo) como motivação semântica do gênero gramatical, outras categorias também podem interagir com o gênero (sexo) e influenciar a classificação dos nomes em gêneros gramaticais". Ele explica que um dos argumentos usados para justificar o uso do masculino genérico na Língua Portuguesa seria a falta de um gênero neutro, porém, refuta esta explicação, citando o exemplo do Latim, em que mesmo possuindo um gênero neutro (além do feminino e do masculino), "era corrente a construção denominada masculino genérico, pois o masculino era o gênero gramatical empregado para denotar 0 gênero humano como um todo" (MÄDER, 2015, p. 73).

Outro ponto a ser destacado na pesquisa de Mäder (2015, p. 97-98) é a discussão da utilização do gênero masculino em outros sistemas semióticos, como nos sinais de trânsito. No caso dos sinais de pedestres, a imagem escolhida para indicar quando a pessoa que está andando deve parar ou pode seguir é, geralmente, a de um homem. Para o autor, "a predominância do masculino na gramática com a predominância do masculino nas relações humanas" (2015, p. 100) é uma comprovação do sexismo no idioma.

Diversos manuais têm sido lançados com a intenção de combater o sexismo do idioma brasileiro. Um dos exemplos é o Manual para o uso não sexista da linguagem (2006), publicado com o apoio da REPEM (Rede de Educação Popular entre Mulheres da América Latina), para ser distribuído pela internet para o Brasil e países africanos de Língua Portuguesa. O guia, inicialmente escrito em espanhol, tem como autoras Julia Pérez Cervera e Paki Venegas Franco (2006) e propõe uma transformação da sociedade a partir da forma de falar e escrever.

apaguem as descrições feminino e masculino, inclusive nos documentos de registro: "cada novo corpo (quer dizer, cada novo contratante) terá um contranome, um novo nome que escape às marcas de gênero, seja qual for a língua empregada" (PRECIADO, 2014, p. 35).

${ }^{3}$ As pesquisas acadêmicas têm como espaço de compartilhamento e aprovação por pares a produção escrita (que é descorporalizada), porém, é possível pensar que, no futuro, outras ferramentas possam servir a visibilizar produções acadêmicas de mulheres e LGBTQI+. Talvez as novas tecnologias e as que já estão estabilizadas, a partir dos próximos anos, possam passar a ser espaços de modelos para publicação acadêmica que valorizem a performance corporal. 
Uma das formas mais sutis de transmitir essa discriminação é através da língua, pois esta nada mais é que o reflexo de valores, do pensamento, da sociedade que a cria e utiliza. Nada do que dizemos em cada momento de nossa vida é neutro: todas as palavras têm uma leitura de gênero. Assim, a língua não só reflete, mas também transmite e reforça os estereótipos e papéis considerados adequados para mulheres e homens em uma sociedade (CERVERA; VENEGAS, 2006).

Os textos trazem conceitos iniciais sobre patriarcado e como a sociedade impõe papéis a serem desempenhados por homens e mulheres, os quais podem estar sendo confirmados e mantidos por meio das palavras. Segundo o Manual, o idioma reforça a desigualdade de gênero e "a única forma de mudar uma linguagem sexista, excludente e discriminatória" é "explicar qual a base ideológica em que ela se sustenta, assim como oferecer alternativas concretas e viáveis de mudança" (CERVERA; VENEGAS, 2006).

Escrito em linguagem bastante simples, explica que a língua é mutável, está em constante evolução, portanto, pode ser alterada. "O problema não está na língua em si", mas no comportamento das pessoas, "nas travas ideológicas, na resistência em dar um uso correto a ela, em utilizar palavras e expressões inclusivas e não discriminatórias para as mulheres". As palavras transmitem os estereótipos e os preconceitos.

Os textos trazem como base diversas autoras, como Simone de Beauvoir e Luce Irigaray, para propor discussões teóricas. Para além das discussões conceituais, há uma parte prática em que são apresentados exemplos de textos sexistas usados comumente em documentos públicos administrativos, seguidos de alternativas que podem servir como ferramentas para uma linguagem mais equitativa e que valorize as mulheres.

Em geral, quisemos fazer um manual com um caráter propositivo porque seu objetivo mais imediato é proporcionar ferramentas que contribuam para "mudar a sociedade atual", pois ao promover que as mulheres sejam nomeadas por elas mesmas estaremos potencializando uma mudança de mentalidades que conduzirão à criação de uma sociedade mais justa e equitativa. Este é o desafio. Esperamos poder contagiar nosso entusiasmo e a ilusão com a qual elaboramos este manual e que sua leitura seja posta em prática sejam um prazer e uma aprendizagem para todas e todos a cujas mãos chegue, da mesma forma que foi para nós (CERVERA; VENEGAS, 2006).

Em 2014, o Governo do Estado do Rio Grande do Sul editou e publicou esse Manual, propondo que dentro das repartições públicas gaúchas se passasse a tê-lo como ferramenta de comunicação. No texto de apresentação, o governador Tarso Genro afirma que o manual "determina e orienta a 'revisão' da linguagem internalizada na administração do Estado" com a intenção de buscar: "a compreensão das discriminações de gênero e, a partir daí, concretamente fazermos a transição para um outro modelo de tratamento linguístico, com maior visibilidade das mulheres e onde o uso do masculino não continue a legitimar a ideia já superada de superioridade de sexo" (2014, p. 9).

O texto de Ariane Leitão (2014), Secretária Estadual de Políticas para as Mulheres, afirma que a igualdade de gênero na linguagem "só será garantida a partir do momento em que se repensar a forma como o tema é tratado nos ambientes educacionais, hoje disseminadores da dominação masculina nos discursos, principalmente quando não identificado o sexo da pessoa a quem se refere" (p. 13). A intenção, com o uso do Manual, era publicizar as ações das mulheres e apresentá-las como sujeitas das atividades históricas em documentos públicos, dando-Ihes visibilidade.

\section{Reflexos da invisibilidade das mulheres nas publicaçōes}

A publicação dos manuais contra o sexismo tende a creditar as mulheres em documentos públicos para que apareçam na história, uma vez que a invisibilidade pode ser refletida em diversos aspectos da sociedade, como nos veículos de comunicação de massa que apresentam fatos históricos em suas notícias. Nas redações de veículos de comunicação ${ }^{4}$ no Brasil, comumente são usadas as expressões: "precisamos de um entrevistado; precisamos entrevistar um especialista". Neste caso, a frase não propõe que o gênero esteja indefinido, neutro, mas que o entrevistado seja um homem.

As fontes jornalísticas nos veículos de comunicação são um exemplo analisado em diversos estudos, inclusive na pesquisa de doutorado em andamento desta autora. Nos primeiros testes de metodologia, já foi possível perceber que há uma preferência por homens como fontes de telejornal. Embora a informação de que homens falam mais que mulheres na televisão seja de domínio público, disponível para qualquer pessoa que assista a um telejornal, é importante

\footnotetext{
${ }^{4}$ A autora atua em diversas redações brasileiras desde 1996, entre emissoras de televisão, rádio, assessoria de imprensa e comunicação e produtoras de conteúdo. Ver currículo lattes: http://lattes.cnpq.br/3128640194028976.
} 
quantificar, perceber representações e lugares sociais das fontes, mas como o estudo está em andamento, os resultados serão divulgados nos próximos anos. ${ }^{5}$

Segundo o censo do Conselho Nacional de Desenvolvimento Científico e Tecnológico (CNPq, 2014), a proporção de pesquisadores homens e mulheres era equivalente no Brasil. Porém, na TV brasileira, a maior parte dos entrevistados são homens brancos e de meia idade, segundo o estudo realizado por Luisa Massarani, Yurij Castelfranchi e Anna Elisa Pedreira (2019), que analisaram, entre abril de 2009 e março de 2010, 169 reportagens do Jornal Nacional e do Fantástico (TV Globo). Em 39\% das reportagens, os cientistas entrevistados eram homens, em $35 \%$ não havia nenhum cientista e em $24 \%$ eram entrevistadas mulheres, sendo a representação predominante a de homem, acima de 40 anos, e branco.

Das 169 unidades identificadas em nosso corpus, 116 são ocupadas por cientistas homens (equivalente a 68,6\%). Em 60 das 169 unidades, o cientista entrevistado (homem ou mulher) é "maduro" (idade aparente acima de 60 anos). A grande maioria dos cientistas representados em nossa amostra (154, ou seja, $91,1 \%)$ é branca. Os demais são assim distribuídos: sete asiáticos $(4,1 \%)$, seis pardos $(3,5 \%)$, 1 negro $(0,6 \%)$ e 1 indígena $(0,6 \%)$ (MASSARANI; CASTELFRANCHI; PEDREIRA, 2019).

O estudo considera que há evidências de uma espécie de silenciamento que "tende a uma construção da invisibilidade" da mulher. Embora, neste caso, não possamos definir esta como uma questão determinada pelo idioma, mas pela cultura, o fato é que pesquisadoras são menos citadas nas publicações científicas e nas publicações jornalísticas, o que torna necessário e urgente trazermos a discussão à tona.

A pergunta que surge após estes dados é: como buscar a igualdade de gênero se a própria Língua Portuguesa for sexista? Davi Silva Gonçalves (2018, p.107) afirma que "uma linguagem sexista nos faz, ainda que inconscientemente, endossar posicionamentos com os quais muitas vezes discordamos". Posicionamentos que podem ser seguidos por conta da tradição de forma inconsciente, mas que atrapalham muito quando se busca o fim da desigualdade.

Giselly Oliveira de Andrade, Gislene Lima Carvalho e Romana Castro Zambrano (2017, p. 441) pesquisaram a representação de gênero em verbetes nos léxicos do idioma, a partir do Minidicionário Aurélio de Língua Portuguesa (Aurélio Buarque de HOLANDA, 2010), e perceberam que a distinção de gênero é bastante expressiva, superior até do que a que se mostra na realidade existente no convívio social, porque "até mesmo nos verbetes daquelas profissões em que há maior concentração de mulheres, a presença do gênero masculino é muito marcante". E apresentam, como exemplo: "nos verbetes educador e enfermeiro no dicionário da língua portuguesa. E, quando neste se é destacado o gênero feminino das palavras, a sua definição é feita de maneira sucinta, como em professora, ou toma como referência o cargo no masculino, como em juíza".

As autoras consideram que o dicionário citado reflete, por um lado, "os discursos da dominação masculina naturalizada nas sociedades" e, por outro, orienta os falantes do idioma contribuindo "para consolidar e conservar os discursos, bem como as sociedades de dominação masculina". Desta forma, é possível considerar que, embora existam dois gêneros gramaticais (feminino e masculino), o masculino pode estar enraizado em nossa cultura falante, por conta da gramática do idioma, como forma de manter a cultura e a história da nossa sociedade.

Se o masculino consegue sintetizar ambos os sexos na representação da Língua Portuguesa, quando há informação de que um é feminino e de que outro é masculino, o que dizer quando os nomes femininos das autoras deixam de ser informados e são trocados apenas por iniciais, mantendo somente seus sobrenomes informados? As normas de publicação que orientam a forma de citação que inicia com o SOBRENOME seguido apenas da INICIAL DO NOME propõem a invisibilidade das autoras mulheres e, portanto, a manutenção da desigualdade.

\section{Como pensar numa saída para visibilizar autoras?}

Os posicionamentos de pesquisadoras como Grada Kilomba, Marcia Tiburi, Adriana Baggio e tantas outras que acreditam na necessidade da valorização da autoria feminina, bem como de sua descrição a partir de nomes, prenomes e pronomes de mulheres, podem iniciar uma pequena transformação nas normas que regem a escritura de artigos científicos, dissertações e teses. Se não trouxerem uma transformação, ao menos, propõem uma discussão acerca do crédito das autoras o qual, no futuro, certamente trará transformações.

Entre as militantes, o uso de "x", “@”, ou até mesmo da letra "e" no lugar do artigo que indica o gênero conseguiu chamar a atenção para o caráter masculino do idioma e para a falta de palavras para se referir ao plural de elementos femininos e masculinos. No Brasil, não é incomum ouvir, entre os mais jovens, as expressões "amigues", "querides", como forma de fugir

${ }^{5}$ A tese a ser defendida em 2021 tem como título: A voz feminina nas reportagens televisivas: um estudo comparativo entre os jornais televisivos de Portugal e do Brasil a partir do lugar de fala. Parte da pesquisa pode ser acompanhada aqui: https://www.youtube.com/watch? $v=2 e L Y N E 40004 \& t=183 \mathrm{~s}$. 
do masculino plural. E, cada vez mais, ouvir alguém cumprimentar uma plateia dizendo: "Boa noite a todas e a todos", ou ler um e-mail se iniciando com "Prezadas professoras e prezados professores" deixa de causar estranheza. Isso denota a transformação do idioma que ainda não chegou aos dicionários.

Esta Revista de Estudos Feministas (REF, 2020) traz em suas normas para publicação a exigência de que as autoras sejam citadas com seu nome na primeira vez que forem apresentadas no texto. Segundo a orientação disponível no site, ${ }^{6}$ "na primeira entrada de citação de cada autora, o prenome completo" deve ser escrito no texto, e, da mesma forma, na lista das referências: "A lista de referências bibliográficas completas, com nome e prenome completos de autoras, deve ser apresentada ao final do texto". Esta é uma forma de valorizar as autoras e mostrar quem são as mulheres referenciadas nas publicações para buscar dar visibilidade ao lugar das mulheres nos textos acadêmicos.

Decisões editoriais como esta são o início da luta pelo reconhecimento das mulheres como autoras e que podem inspirar outras publicações. Também, podem inspirar decisões individuais, como a minha, quando decidi discutir sobre a necessidade de uma creditação mais igualitária e justa para mulheres. Podemos estar vivendo um momento de pequenas transformações que merecem ser levantadas e discutidas na academia, entre alunas, alunos, professoras e professores. Quem sabe, no futuro, teremos uma transformação de nosso idioma.

Já existem várias pesquisadoras que divulgam ter tomado como decisão pessoal escrever os nomes completos das autoras e autores. Claudia Quadros e Maria Santos (2019), em vez de escreverem nas referências bibliográficas de seus trabalhos recentes apenas o sobrenome da fonte e a inicial do nome, citam a autora na forma completa, como, por exemplo: "RECUERO, Raquel. Redes sociais na internet. Porto Alegre: Sulina, 2009". Este é o caminho fácil de ser seguido por todas e todos em suas publicações.

Adriana Baggio (2019) propõe, também, outras duas formas que servem para reduzir a invisibilidade das autoras. Ela sugere creditar os nomes completos das tradutoras das obras (já que a maioria das profissionais deste setor são mulheres) e, ainda, usar os pronomes corretos. Ela cita: "Pabllo Vittar, por exemplo, apesar de ter um primeiro nome que identificamos como masculino, usa o pronome no feminino. Então, se for mencioná-la - como já precisei fazer em um artigo -, use 'ela", 'a cantora' etc.".

Cabe a nós, pesquisadoras, decidirmos por combater a invisibilidade, aproveitando os exemplos de colegas pesquisadoras que questionam, criticam e justificam o uso de nossos nomes completos, dos pronomes adequados, para dar crédito às produções femininas. Ao escrever essa frase, o corretor eletrônico do Microsoft Word, para confirmar minha hipótese, teima em deixar a palavra pesquisadoras sublinhada em vermelho e me pergunta se eu quis dizer: pesquisadores.

Figura 2: Microsoft Word corrige para o masculino

Cabe a nós pesquisadoras, decid exemplos de colegas pesquisadoral nomes completos, dos pronomes a escrever essa frase, o corretor eletr deixar a palavra pesquisadoras su pesquisadores.
Você quis dizer:

pesquisadores

Feedback sobre a sugestão

Ignorar tudo

Sempre corrigir para "pesquisadores"

Fonte: Print da tela do computador da autora.

\#PraTodoMundoVer: Imagem de uma captação de tela do computador deste próprio texto, aparecendo a frase: exemplos de colegas pesquisadoras que questionam e justificam o uso de nossos nomes completos, dos pronomes... O Word destaca a palavra pesquisadoras e abre uma tela onde aparece o texto: Você quis dizer: pesquisadores.

A palavra ficará sublinhada no arquivo em meu texto no Google Drive, para me lembrar de que precisamos lutar. Da mesma maneira que tive contato, há pouco mais de um ano, com autoras que brigam por sermos valorizadas na academia, e resolvi começar a usar em meus textos os nomes completos das mulheres que são minhas fontes, outras mulheres podem agir assim. Em meus textos anteriores, sempre segui à risca as normas de publicação exigidas pelas revistas, congressos, livros etc. por medo de não conseguir publicar, por medo de ter meu texto devolvido, entre outros medos.

6 Para consultar as normas da Revista Estudos Feministas: https://periodicos.ufsc.br/index.php/ref/about/ submissions\#authorGuidelines. 
Agora, em orientações de Trabalhos de Conclusão de Curso e de Projetos de Iniciação Científica, sempre indico a minhas alunas e alunos para incluir os nomes e sobrenomes de autores e autoras, explicando a questão da visibilidade da mulher pesquisadora, e os convido a praticar a referenciação completa em seus textos científicos. A partir de agora, vou justificar o motivo de não usar mais apenas iniciais para apresentar autoras e autores em qualquer de meus textos. E seguir apresentando as referências bibliográficas como as que seguem abaixo.

\section{Referências}

ANDRADE, Giselly Oliveira de; CARVALHO, Gislene Lima; ZAMBRANO, Romana Castro. "A representação do gênero em dicionários monolíngues dos idiomas alemão, espanhol e português: uma análise crítica feminista de verbetes referentes às profissões". Calidoscópio [online], Unisinos, v. 15, n. 3, p. 433-442, set./dez. 2017. Disponível em https://www.researchgate. net/publication/323232330 A representacao do genero em dicionarios monolingues dos idiomas_alemao_espanhōl_e_portugues_uma_analise_critica feministäde verbetes referentes_as_profissoes. Acesso em 18/02/2020.

BAGGIO, Adriana Tulio. "Como agradar uma mulher com a língua". Medium [online], Curitiba, 19/02/2020. Disponível em https://medium.com/@adrianabaggio/como-agradar-uma-mulherusando-a-1\%C3\%ADngua-d884bac77fad. Acesso em 20/04/2020.

BRASIL. Presidência da República. Decreto $n^{\circ}$ 8.727. Lei que dispõe sobre o uso do nome social e o reconhecimento da identidade de gênero de pessoas travestis e transexuais no âmbito da administração pública federal direta, autárquica e fundacional [online], 2016. Disponível em http:/l www.planalto.gov.br/ccivil_03/_Ato2015-2018/2016/Decreto/D8727.htm. Acesso em 01/09/2019.

BUTLER, Judith. Problemas de Gênero: Feminismo e Subversão da Identidade. Rio de Janeiro: Civilização Brasileira, 2003.

CERVERA, Julia Pérez; FRANCO, Paki Venegas. Manual para o uso não sexista da linguagem. $O$ que bem se diz... bem se entende [online]. REPEM (Rede de Educação Popular entre Mulheres da América Latina), 2006. Disponível em http://www.observatoriodegenero.gov.br/menu/publicacoes/ outros-artigos-e-publicacoes/manual-para-o-uso-nao-sexista-da-linguagem. Acesso em 22/01/2018.

CNPq. Conselho Nacional de Desenvolvimento Científico e Tecnológico. $10^{\circ}$ Censo do Diretório dos Grupos de Pesquisa no Brasil [online], 2014. Disponível em http://lattes.cnpq.br/web/dgp/ censo-atual/. Acesso em 20/01/2018.

DALCASTAGNÉ, Regina. "Um território contestado: literatura brasileira contemporânea e as novas vozes sociais". Iberic@I Revue d'études ibériques et ibéro-américaines [online], n. 2, p. 13-18, 2012. Disponível em http://iberical.paris-sorbonne.fr/wp-content/uploads/2012/03/002-02.pdf. Acesso em 21/01/2019.

ELSEVIER. Gender in the Global Research Lanscape [online], 2017. Disponível em https://www. elsevier.com/_data/assets/pdf file/0008/265661/ElsevierGenderReport final for-web.pdf. Acesso em 20/01/2018.

ESTADÃO. Perfil oficial do jornal O Estado de S. Paulo no Instagram. "Pabllo Vitar é nova garota propaganda da Calvin Klein em Campanha LGBT", 2020. Disponível em https://www.instagram. com/p/CAN6LwVjY1n/?igshid=61vodjod1400. Acesso em 15/05/2020.

FARIAS, Salete Silva; MARTINS, Alcina de Oliveira. "Invisibilidade Feminina e Representações Sociais de Gênero em Tecnologia e Ciências". 120 CONGRESSO NACIONAL DE PSICOLOGIA DA SAÚDE [online]. Actas. Lisboa, 2018. Disponível em http://repositorio.ispa.pt/ bitstream/10400.12/6246/1/12CongNacSaude 731.pdf. Acesso em 21/01/2020.

GONÇALVES, Davi Silva. "Por uma língua feminista: uma breve reflexão sobre o sexismo linguístico". Revista Interdisciplinar em Cultura e Sociedade (RICS), São Luís, v. 4, n. 1, 2018. Disponível em http://www.periodicoseletronicos.ufma.br/index.php/ricultsociedade/article/view/9317.

HOLANDA, Aurélio Buarque de. Minidicionário Aurélio de Língua Portuguesa. 8. ed. Curitiba: Positivo, 2010.

KILOMBA, Grada. Memórias da Plantação. Episódios de Racismo Cotidiano. Rio de Janeiro: Cobogó, 2019. 
LEITÃO, Ariane. "Mais visibilidade para as mulheres". In: TOLEDO, Leslie Campaner de; ROCHA, Maria Anita Kieling da; DERMMAN, Marina Ramos; DAMIN, Marzie Rita Alves; PACHECO, Mauren (Orgs.). Manual para o uso não sexista da linguagem. O que bem se diz... bem se entende, 2014. Disponível em http://www.observatoriodegenero.gov.br/menu/publicacoes/outros-artigose-publicacoes/manual-para-o-uso-nao-sexista-da-linguagem. Acesso em 22/01/2018.

MÄDER, Guilherme Ribeiro Colaço. Masculino genérico e sexismo gramatical. 2015. Mestrado (Pós-Graduação em Linguística) - Universidade Federal de Santa Catarina, Florianópolis, SC, Brasil.

MARCHA MUNDIAL DAS MULHERES. A marcha. Nossa história. Marcha Mundial das Mulheres. Disponível em https://www.marchamundialdasmulheres.org.br/a-marcha/nossa-historia/. Acesso em 10/01/2020.

MASSARANI, Luisa; CASTELFRANCHI, Yurij; PEDREIRA, Anna Elisa. "Cientistas na TV: como homens e mulheres da ciência são representados no Jornal Nacional e no Fantástico". Cadernos Pagu, Campinas, n. 56, 2019. Disponível em http://www.scielo.br/scielo. php?pid=S010483332019000200505\&script=sci_arttext\&tlng=pt. Acesso em 27/02/2020.

NODARI, Sandra. "Facebook as a video production and exhibition platform used by journalism students: a case study of Rede Teia (Brazil)". WJEC-PARIS: WORLD JOURNALISM EDUCATION COUNCIL CONGRESS, Annals... Paris, 2019.

PORTUGAL. Parlamento Português, 2019. Lei n. ${ }^{\circ} 7 / 2011$, de 15 de março de 2011. Cria o procedimento de mudança de sexo e de nome próprio no registo civil e procede à décima sétima alteração ao Código do Registro Civil. Disponível em http://app.parlamento.pt/webutils/ docs/doc.8664e3138794d4445784c6e426b5a673d3d\&fich =L_7_2011.pdf\&Inline=true. Acesso em 01/09/2019.

PRECIADO, Beatriz. Manifesto Contrassexual. Tradução de Maria Paula Gurgel Ribeiro. São Paulo: n-1 edições, 2014.

QUADROS, Claudia; SANTOS, Maria L. S. dos. "Interação e satisfação de trabalhadores da base fabril no Facebook". Inovação e Empreendedorismo em Comunicação (Organicom), v. 16, n. 31, 2019. Disponível em https://www.revistas.usp.br/organicom/article/view/158377. Acesso em $27 / 01 / 2020$.

REF. REVISTA ESTUDOS FEMINISTAS. Submissões, 2020. Disponível em https://periodicos.ufsc.br/index. php/ref/about/submissions\#authorGuidelines. Acesso em 01/11/2020.

ROCHA, Rose de Melo; POSTINGUEL, Danilo K. O. "O nocaute remix da drag Pabllo Vittar". Revista E-Compós - Associação Nacional dos Programas de Pós-Graduação em Comunicação (Compós) [online], Brasília, v. 20, n. 3, 2017. Disponível em https://www.e-compos.org.br/ecompos/article/view/1416/951. Acesso em 27/02/2020.

RUBIO, Cássio Florêncio; TORRES, Fábio Fernandes. "Presidente ou presidenta? Com a palavra os senadores e as senadoras da República Federativa do Brasil". Revista de Estudos da Linguagem [online], Belo Horizonte, v. 26, n. 1, p. 491-524, 2018. Disponível em https://www.researchgate. net/publication/321385936 Presidente_ou_presidenta_Com_a_palavra_os senadores_e_as senadoras da Republica Féderativa do Brasil. Acesso em 01/1 1/1/2020.

SANTOS, Raquel da Conceição; PINHEIRO, Hellen Rafaela Figueiredo; HAGE, Maria do Socorro Castro. "Mulheres e Produção do Conhecimento Científico: uma reflexão necessária". VI CONGRESSO NACIONAL DE EDUCAÇÃO (CONEDU) [Online], Anais... Fortaleza, 2019. Disponível em https://editorarealize.com.br/artigo/visualizar/61165. Acesso em 01/11/2020.

SOARES, Sandro V.; PICOLLI, Icaro R. A.; CASAGRANDE, Jacir L. "Pesquisa Bibliográfica, Pesquisa Bibliométrica, Artigo de Revisão e Ensaio Teórico em Administração e Contabilidade". Administração: Ensino e Pesquisa [online], Rio de Janeiro, v. 19, n. 2, p. 308-339, 2018. Disponível em https://raep.emnuvens.com.br/raep/article/view/970. Acesso em 20/02/2020.

SUPREMO TRIBUNAL FEDERAL. Ação Direta de Inconstitucionalidade 4.275 Distrito Federal. Inteiro Teor do Acórdão, 2018. Disponível em https://redir.stf.jus.br/paginadorpub/paginador. isp? docTP=TP\&docID =749297200. Acesso em 01/09/2019.

TIBURI, Marcia. Feminismo para Todas, Todes e Todos. Rio de Janeiro: Rosa dos Tempos, 2018. $126 \mathrm{p}$. 
WOOLF, Virgínia. Um Teto Todo Seu. Tradução de Bia Nunes de Sousa e Glauco Mattoso. Rio de Janeiro: Livraria da Travessa, 2014.

Sandra Nodari (sandra.nodari@up.edu.br) é doutora em Ciências da Informação pela Universidade Fernando Pessoa (Portugal) em cotutela com o programa de doutorado em Comunicação da Universidade Federal do Paraná (2021), mestre em Comunicação e

\section{COMO CITAR ESTE ARTICO DE ACORDO COM AS NORMAS DA REVISTA}

NODARI, Sandra. "Nomes e pronomes na Língua Portuguesa: a questão sexista no idioma e na academia". Revista Estudos Feministas, Florianópolis, v. 29 n. 3, e74197, 2021.

\section{CONTRIBUIÇĀO DE AUTORIA}

Não se aplica.

\section{FINANCIAMENTO}

Não se aplica.

\section{CONSENTIMENTO DE USO DE IMAGEM}

A imagem 1 é de perfil público do Instagram, fornecida como material de divulgação da ex-presidenta Dilma Roussef. A imagem 2 é de autoria própria.

\section{APROVAÇĀO DE COMITÊ DE ÉTICA EM PESQUISA}

Não se aplica.

\section{CONFLITO DE INTERESSES}

Não se aplica.

\section{LICENÇA DE USO}

Este artigo está licenciado sob a Licença Creative Commons CC-BY 4.0 International. Com essa licença você pode compartilhar, adaptar, criar para qualquer fim, desde que atribua a autoria da obra.

\section{HISTÓRICO}

Recebido em 25/05/2020

Reapresentado em 06/1 1/2020

Aprovado em 01/02/2021

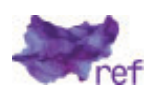

